\title{
STUDY OF ADHESION PROPERTIES OF NATURAL RUBBER - BASED PRESSURE SENSITIVE ADHESIVE WITH VARIATION OF TACKIFIER RESIN AND PLASTICIZERS AGENTS
}

\author{
F. B. M. SILVA ${ }^{1}$, R. F. VIANNA ${ }^{1}$ e I. NEUBERT ${ }^{2}$ \\ ${ }^{1}$ Universidade Federal da Bahia, Chemical Engineering Department \\ 2 tesa SE, Natural Rubber Adhesive Research and Development Department \\ E-mail for contact: 1leo.felipe@ hotmail.com
}

\begin{abstract}
Pressure sensitive adhesives (PSA) are special adhesives that exhibit tack at room temperature. The objective of this study is to establish a methodology for testing formulations for pressure sensitive adhesives, to find out which ones give higher value for peel adhesion, while keeping good performance for all other properties. Formulations were prepared in laboratory, based on a statistical Design of Experiments, varying the amount of two different types of plasticizer and one type of resin. The choice of those three components was based on experience. Contour line diagrams, created by the statistical software Design Expert, were used to analyse which formulations give better results. Finally, samples with the best outcomes were reproduced and their results compared with the forecast of the statistical model. The methodology proved to be adequate, leading to the manufacture of new optimized samples.
\end{abstract}

\section{INTRODUCTION}

Adhesives are synthetic substances, usually polymers, that are capable of holding two materials glued together. They can be produced from a solvent-based technology (aqueous or organic) or from a solvent-free one (the so-called hot melt adhesives). The pressure sensitive adhesives (PSA) are special adhesives that exhibit tack at room temperature. Because of this, they firmly adhere to a variety of different surfaces after brief contact by using only hand pressure. They are generally made from a base polymer, tackifier resins, plasticizers oils and antioxidants. The base polymer and resins are responsible for the adhesive's flexibility and tack; oils facilitate the processing, improve flexibility and influence viscosity; antioxidants additives, in turn, aim to reduce oxidation of the adhesive (Fernandes, 2010). Due to its increasing industrial importance, pressure sensitive systems have been investigated, mainly in an attempt to explain and predict its mechanical properties (Horgnies et al., 2007; Derail and Marin, 2006; Guillemenet et al., 2002). However, the technology for formulating PSA still presents a predominantly empirical character (Derail and Marin, 2006), due to the difficulty to establish quantitative relationships between rheological behavior, adhesive properties and composition.

The solvent-free process use is largely growing nowadays, due to the economic and 


\section{9 a 22 de outubro de 2014 \\ Florianópolis/SC}

environmental benefits. In recent years, studies have been conducted in order to understand and explain the mechanical properties of the PSA, seeking to relate these characteristics to their compositions, aiming at a better association with the final application (Fernandes, 2010). The tesa SE, a german company, has successfully implemented a solvent-free technology to produce natural rubber-based adhesive tapes. Currently, the company aims to change the production process of some products from the solvent-based method to a solvent-free one. However a simple one-to-one transfer of the adhesive formulation proved to be problematic.

This study, undertaken within tesa SE company, has focused on the development and study of PSA formulations, by varying two plasticizing oils and one type of resin. A preliminary formulation was implemented in a pilot plant, known as \#145. This has very good properties, in general, but the adhesion characteristics are too low. Therefore this study aims at developing a methodology for new formulations for PSA, to find out which one gives the higher value of peel adhesion, while maintaining all other properties.

\section{MATERIALS AND METHODOLOGY}

\subsection{Equipment and Materials}

Due to confidentiality clauses, this study will not publish the real names of the formulation components, some operating parameters and other confidential data. Therefore, the two types of resin and the two types of plasticizers will be named just as resin A and B and plasticizer A and B.

Raw materials used for the samples production were: natural rubber, zinc oxide, antioxidants, resin A, resin B, plasticizer A, plasticizer B and benzine. Main equipment used were a kneader Linden model LK II-1, a coating table and a tensile test machine.

\subsection{Methodology}

The Response Surface Method (RSM) was used to carry out the statistical experimental design in order to determine the influence and interactions of certain components of the PSA formulation. The commercial software tool Design Expert, from the U.S. Company Stat-Ease Inc., was used.

According to Eldin (2011), if the combinations of $\mathrm{k}$ factors are investigated at two levels, a factorial design will consist of $2^{\mathrm{k}}$ experiments. Therefore, three experimental factors were chosen (plasticizers A and B and the resin B), leading to eight samples. Three center points, that estimate the dispersion of random errors, were also included. The results are showed in Table 1.

The calculation of the formulations was based on a typical weight used in the adhesive industry, which is classified in 100 parts of rubber (phr - per hundred rubber). The adhesives were produced from solvent based process with benzine. Although the target goal of development is aligned with a pressure-sensitive adhesive for solvent-free process, the preparation of the laboratory sample is done on a solvent base. The solvent-based preparation is simpler to implement in the laboratory and requires only a smaller amount of raw materials. The measurement results obtained allow a relative 
assessment of the influence of the individual components.

Table 1 - Formulations of the PSA samples \#145 to A11

\begin{tabular}{|c|c|c|c|c|c|c|c|c|c|c|c|c|}
\hline & & & & & rmula & ion (pl & & & & & & \\
\hline & \#145 & A 1 & A 2 & A 3 & A 4 & A 5 & A 6 & A 7 & A 8 & A 9 & A 10 & A 11 \\
\hline $\begin{array}{l}\text { Natural } \\
\text { Rubber }\end{array}$ & 100,0 & 100,0 & 100,0 & 100,0 & 100,0 & 100,0 & 100,0 & 100,0 & 100,0 & 100,0 & 100,0 & 100,0 \\
\hline Zinc Oxide & 74,5 & 74,5 & 74,5 & 74,5 & 74,5 & 74,5 & 74,5 & 74,5 & 74,5 & 74,5 & 74,5 & 74,5 \\
\hline Resin A & 54,3 & 54,3 & 54,3 & 54,3 & 54,3 & 54,3 & 54,3 & 54,3 & 54,3 & 54,3 & 54,3 & 54,3 \\
\hline Resin B & 54,0 & 54,0 & 70,0 & 54,0 & 54,0 & 70,0 & 62,0 & 70,0 & 62,0 & 62,0 & 70,0 & 54,0 \\
\hline Plasticizer A & 57,4 & 45,0 & 57,0 & 57,0 & 45,0 & 45,0 & 51,0 & 57,0 & 51,0 & 51,0 & 45,0 & 57,0 \\
\hline Plasticizer B & 13,5 & 6,0 & 13,0 & 6,0 & 13,0 & 6,0 & 9,5 & 6,0 & 9,5 & 9,5 & 13,0 & 13,0 \\
\hline Antioxidants & 6,9 & 6,9 & 6,9 & 6,9 & 6,9 & 6,9 & 6,9 & 6,9 & 6,9 & 6,9 & 6,9 & 6,9 \\
\hline
\end{tabular}

The production and coating of the adhesive was conducted on the kneader equipment, which is responsible for the mixing and homogenization of the adhesive mass. In general it is produced a white and viscous paste, with the characteristic odor of benzine. After a period of 12 hours, the adhesive is conducted to a coating process and analysed. The coating is made over one liner, often composed of silicon-coated paper or PET, by using a large metal table with air holes at the edges. Samples are stored covered with paper separation sheets.

Tensile tests were conducted in order to determine the strength of the interaction between the adhesive and different surfaces. Room temperature is kept around $23^{\circ} \mathrm{C}\left(+/-1^{\circ} \mathrm{C}\right)$ and relative air humidity of $50 \%(+/-5 \%)$.

A piece of tape was applied to a surface and then was removed with the aid of a tensile test machine. Force, in N/cm, required to remove the tape is called peel adhesion. Two surfaces were chosen: steel (standard) and the backing of the tape (coated fabric).

After the formulation and tests of the samples, experimental data were used to feed the software referred earlier in order to generate a mathematical model for the process. These models are represented as response surfaces relating the influence between tested parameters process response (Scholz, 2013).

\section{RESULTS AND DISCUSSIONS}

Table 2 and Figure 1 show peel adhesion tests performed on steel and coated fabric. In the case of the fabric surface, tests were conducted in two different situations: (a), the strip was attached to the surface and tested fresh at room conditions; (b), the tape was attached to the surface and stored in an oven at $40^{\circ} \mathrm{C}$ for 24 hours.

Results show that sample \#145 has a peel adhesion on steel of 2,0 N/cm, which is lower than desired value, which is around $3,3 \mathrm{~N} / \mathrm{cm}$, while keeping it on fabric after storage as little as possible. 
Except for the sample A11, which is the reproduction of the \#145, all other ones presented a value higher than 2,0 N/cm, showing that the selected experimental space was correct. Sample A5 is noteworthy, since it showed the highest values of peel adhesion. However, this was expected, since its formulation had the highest amount of resin and the lowest of plasticizer.

Table 2 - Results of peel adhesion of samples \#145 to A11

\begin{tabular}{|c|c|c|c|c|c|c|c|c|c|c|c|c|}
\hline \multicolumn{13}{|c|}{ Peel Adhesion (N/cm) } \\
\hline & \#145 & A 1 & A 2 & A 3 & A 4 & A 5 & A 6 & A 7 & A 8 & A 9 & A 10 & A 11 \\
\hline Steel & 2,0 & 3,4 & 3,4 & 3,1 & 2,8 & 4,7 & 3,4 & 3,9 & 3,2 & 3,2 & 3,4 & 2,4 \\
\hline Fabric & 1,3 & 2,3 & 2,3 & 2,0 & 2,1 & 3,0 & 2,5 & 2,9 & 2,1 & 2,1 & 2,4 & 1,7 \\
\hline $\begin{array}{c}\text { Fabric after } \\
\text { storage }\end{array}$ & 2,8 & 3,9 & 4,0 & 3,8 & 3,7 & 5,5 & 4,3 & 5,3 & 3,7 & 3,8 & 4,0 & 3,0 \\
\hline
\end{tabular}

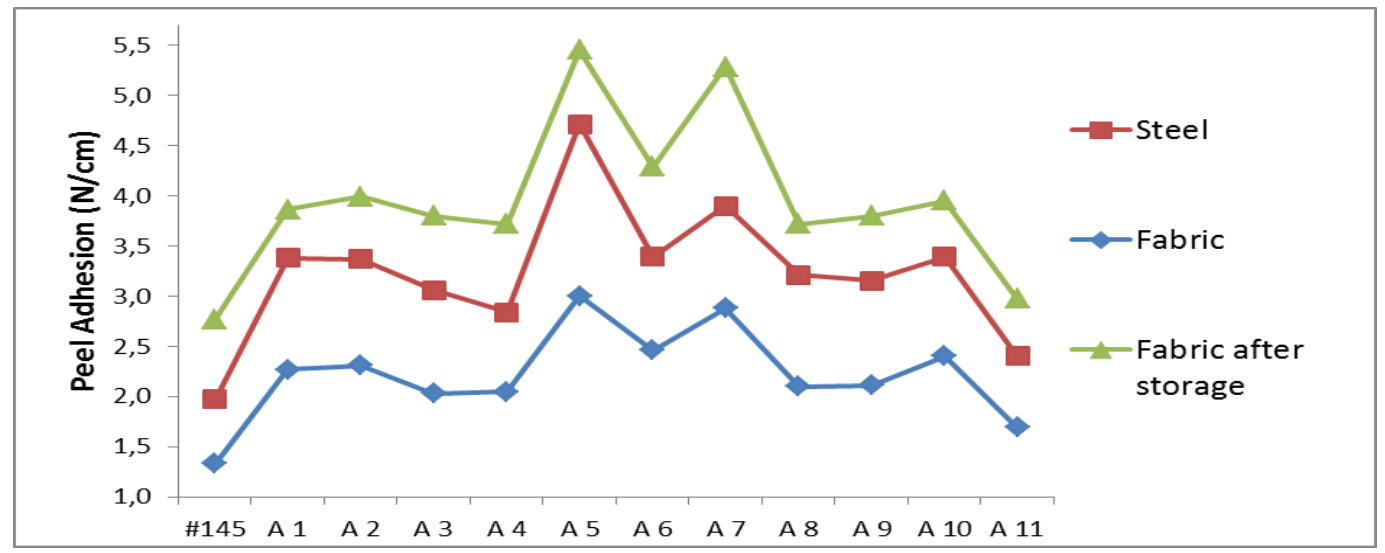

Figure 1 - Results of peel adhesion of samples \#145 to A11.

Besides, test values for steel are always higher than for the fabric ones. This is due to the physical adsorption, which plays a very important role on the adherence. The polarity of adhesive can improve physical adsorption between adhesive and bonded substrates. Metal is a polar material and it adheres easier on any adhesives. Fabric, in comparison to the steel, is a very rough surface, which makes the adhesive harder to conform to it. In addition, the fabric is glazed with a special paint finish, to keep the bond strengths deliberately low to ensure an easy unrolling from the roll (Scholz, 2013). It should also be noted that the values for peel adhesion after storage in the oven are higher than fresh values. This happens because the adhesive becomes more fluid at high temperatures, becoming easier to fit in the irregularities of the test plate surface.

Comparing these results with the formulations showed at Table 1, one may infer how each component influence the adherence. Formulations that contain more resin and less plasticizer (e.g., samples A5 and A7) presented highest values of peel adhesion. This was expected, since the resin offers high tackifier properties when used in formulations with natural rubber (Satas, 1989). Besides, as showed by Jugendheimer (2012), small amounts of oil increase the tack in pressure sensitive 
adhesives based on natural rubber. However, at the same time, occurs a decrease in the adhesive strength and thermal stability.

Afterwards, experimental data were fed to the software tool Design Expert, which based on statistical analyses calculated, with a $\mathrm{R}^{2}$ of 0,9351 , the best model for the process that came to be a linear one (Equation 1).

$$
\hat{y}=\aleph_{0}+\aleph_{1} A+\aleph_{2} B+\aleph_{3} C
$$

where $\hat{y}$ is the predicted response, $\beta_{0}$ is the intercept and $\beta_{1}, \beta_{2}$ and $\beta_{3}$ are the model coefficients for the factors A, B and C, respectively. This model was used as the basis to predict the values of the Peel Adhesion and Shear Strength. For each response, the coefficients of the equation were adjusted. The most important parameter to be evaluated is the growth of the peel adhesion on the steel surface. Therefore, only these results will be discussed here. However, it should be emphasized that similar analyses were made for the other properties.

Figure 2 shows the model coefficients regarding the peel adhesion on steel. As expected, the resin tends to increase the adhesion of the adhesive and has the biggest influence of all the components. Both plasticizers influence the peel adhesion in a negative way, although the plasticizer B showed a stronger effect, almost as strong as the resin. Therefore, only the combined effects of resin $\mathrm{B}$ and plasticizer $\mathrm{B}$ will be further investigated in this work.

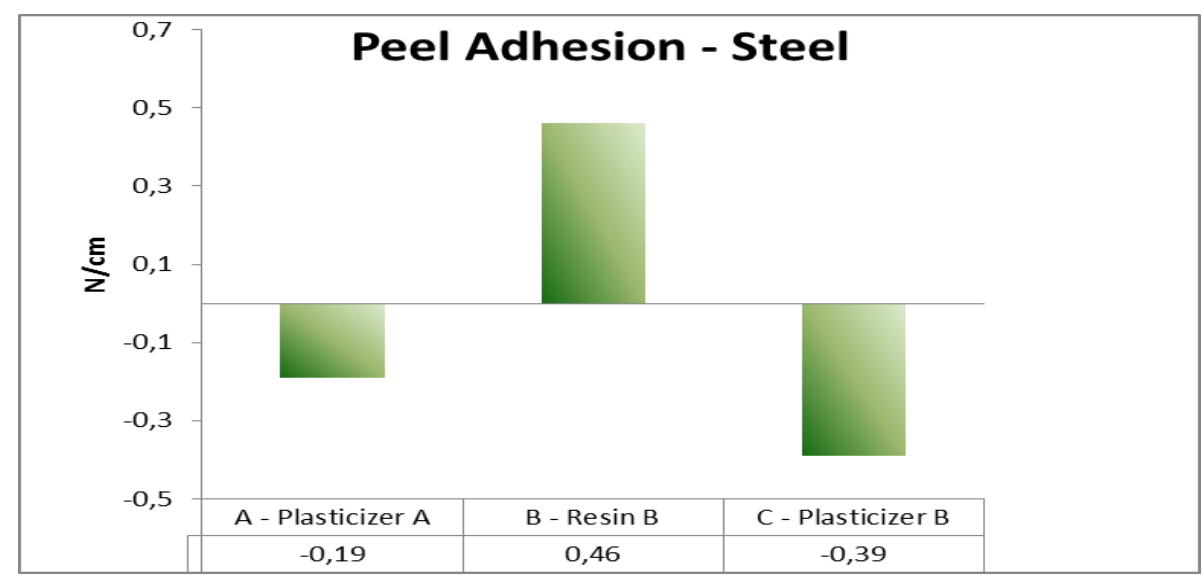

Figure 2 - Model coefficients for peel adhesion on steel surface.

As already stated, the objective is to increase the peel adhesion value from $2,0 \mathrm{~N} / \mathrm{cm}$ to 3,3 $\mathrm{N} / \mathrm{cm}$. Contour line diagrams (Figure 3) allow the visualization of the effects of changing two independent variables while keeping other constants. Here, the amount of plasticizer A was hold constant. Figure 3 shows that when the plasticizer B is set to the minimum (6 phr) and the resin is set for a value between 58 and $62 \mathrm{phr}$, the goal is achieved. 


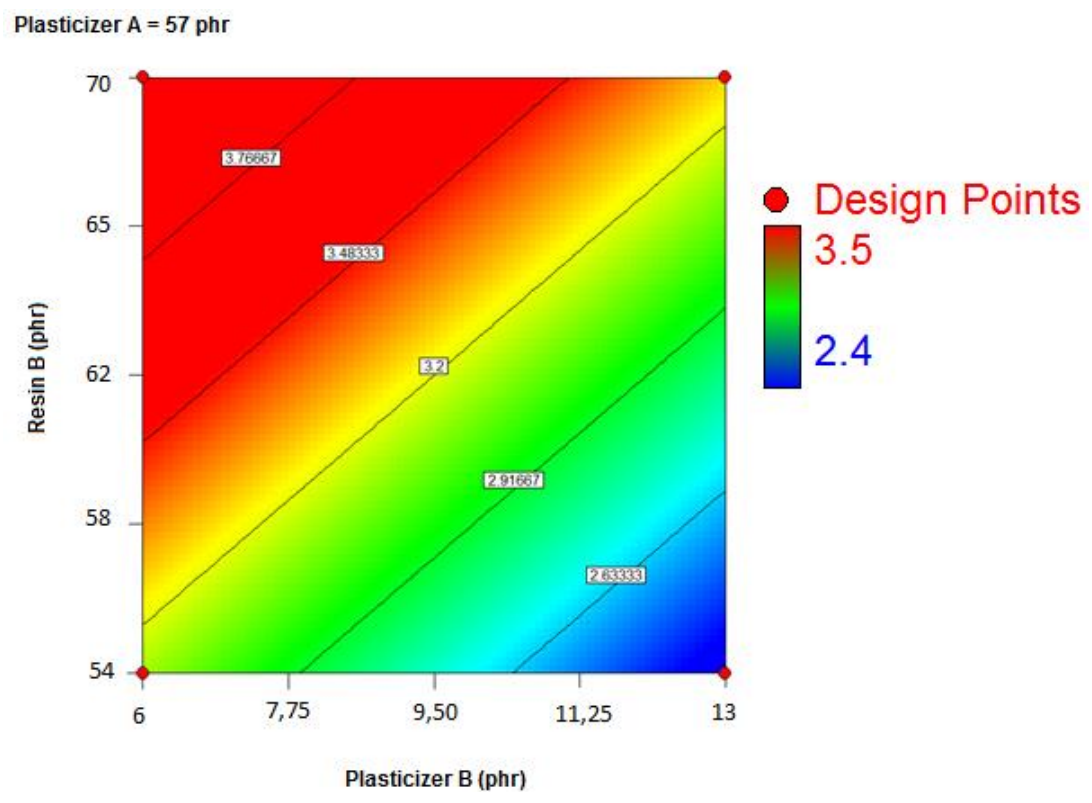

Figure 3 - Contour line diagram between resin B and plasticizer B.

In addition to the improvement of peel adhesion on steel, it is also desired that the best formulation achieves a minimum peel adhesion on the coated fabric after storage and a minor value of shear strength. The Design Expert software takes these requirements and creates a desirability algorithm (optimization based on objective functions), which determines the optimal formulations. The desirability values indicate when the specified target values are met (Scholz, 2013).

Desirability curves for resin B and plasticizer B are shown in Figure 4. Blue areas indicate regions where the requirements are not achieved. In the color-graded areas, recipes can meet the criterions to a certain percentage. The maximum achievable desirability within the chosen test area is $71,0 \%$ (red area), achieved when the resin B is at its lowest limit of $54 \mathrm{phr}$ and the plasticizer B is maintained around 7,7 phr.

Finally, based on previous results, five additional samples closer to the optimal formulation were produced. Sample A12 is a reproduction of Sample A3, which showed good results; samples A13, A14 and A15 are variations of the sample A12; sample A16 is a variation of the sample A10. Table 3 contains the formulation of those new samples, while Figure 5 shows their peel adhesion results compared to the sample \#145. 


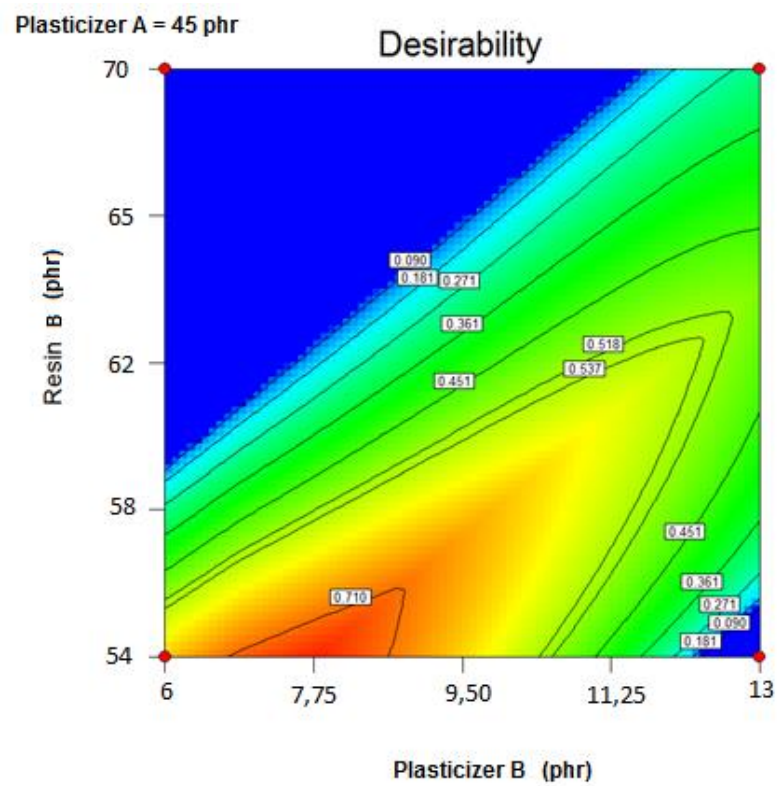

Figure 4 - Desirability curve between resin B and plasticizer B.

Table 3 - Formulations of the optimized PSA samples

\begin{tabular}{ccccccc}
\hline & \multicolumn{7}{c}{ Formulation (phr) } & & & \\
& $\mathbf{\# 1 4 5}$ & $\mathbf{A ~ 1 2}$ & $\mathbf{A ~ 1 3}$ & $\mathbf{A ~ 1 4}$ & $\mathbf{A ~ 1 5}$ & $\mathbf{A} \mathbf{1 6}$ \\
\hline Natural Rubber & 100,0 & 100,0 & 100,0 & 100,0 & 100,0 & 100,0 \\
\hline Zinc Oxide & 74,5 & 74,5 & 74,5 & 74,5 & 74,5 & 74,5 \\
\hline Resin A & 54,3 & 54,3 & 54,3 & 54,3 & 54,3 & 54,3 \\
\hline Resin B & 54,0 & 54,0 & 56,0 & 54,0 & 58,0 & 54,0 \\
\hline Plasticizer A & 57,4 & 57,0 & 57,0 & 57,0 & 57,0 & 45,0 \\
\hline Plasticizer B & 13,5 & 6,0 & 6,0 & 7,5 & 7,5 & 10,0 \\
\hline Antioxidants & 6,9 & 6,9 & 6,9 & 6,9 & 6,9 & 6,9 \\
\hline
\end{tabular}

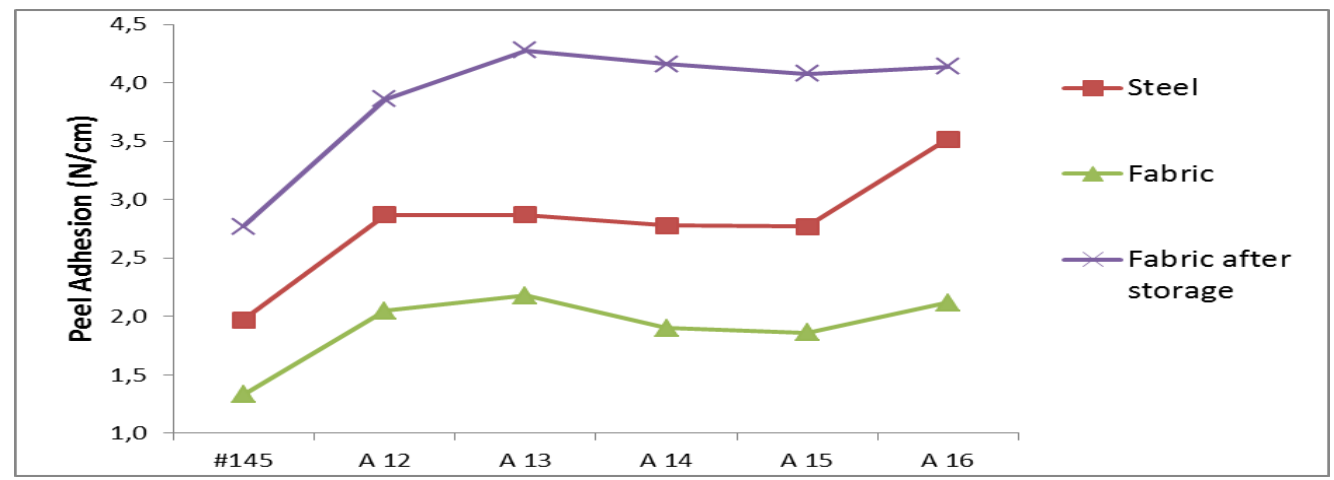

Figure 5 - Results of peel adhesion of the optimized samples. 
It can be seen that samples A12 to A15 present similar results for the peel adhesion on steel, while the sample A16 presents a higher value, probably due the lower amount of the plasticizer A, around 3,35 N/cm, showing an improvement compared to the sample \#145. The values for the peel adhesion on the fabric after storage are not as low as some of the previous samples, because the optimization of the formulations affects not only the peel adhesion on steel, but also on other surfaces, in general.

\section{CONCLUSION}

New optimized pressure sensitive adhesives (PSA) formulations from natural rubber, based on the \#145 sample, were developed with improved adhesion properties. The variation of only one resin and two plasticizers was enough to achieve the goal of peel adhesion on steel surface of, approximately, $3,3 \mathrm{~N} / \mathrm{cm}$, while maintaining acceptable values of peel adhesion on the tape's backing. Therefore, the methodology proved to be adequate, leading to the manufacture of new optimized PSA samples.

\section{ACKNOWLEDGMENTS}

This study was supported by tesa SE, through an internship program sponsored by Brazilian Government through its Ciência Sem Fronteiras exchange program, in partnership with CAPES and DAAD.

\section{REFERENCES}

DERAIL, C., MARIN, G. Rheology and adherence of pressure-sensitive adhesives. The J. of Adhe., v. 82, p. 469-485, 2006.

ELDIN, A. B. Wide Spectra of Quality Control. Publisher: InTech, 2011.

FERNANDES, C. Estudo das propriedades mecânicas e reológicas de adesivos Hot Melt PSA com variação de plastificantes e elastômeros. Universidade de Feevale, Novo Hamburgo, 2010.

GUILLEMENET, J., BISTAC, S., SCHULTZ, J. Relationship between polymer viscoelastic properties and adhesive behaviour. Inter. J. of Adhe. and Adhes., v. 22, p. 1-5, 2002

HORGNIES, M., DARQUE-CERETI, E., FELDER, E. Relationship between fracture energy and the mechanical behaviour of pressure sensitive adhesives. Inter. J. of Adhe. and Adhes., v. 27, p. 661-668, 2007.

JUGENDHEIMER, M. Lösemittelfreie Naturkautschuk-Klebmassen. Hochschule Lausitz, Senftenberg, 2012.

SATAS, D. Handbook of pressure sensitive adhesive technology. United States: Vnr Publishers, 1989.

SCHOLZ, M. Entwicklung von Naturkautschuk-Haftklebmasse auf Basis lösungsmittelfreier Technologien. Technische Universität Dresden, Dresden, 2013. 